\title{
LAMBLIASIS AS A CAUSE OF CHRONIC ENTERITIS IN CHILDREN.
}

\author{
BY \\ REGINALD MILLER, M.D., F.R.C.P. \\ (From Paddington Green Children's Hospital.)
}

Intestinal infections due to the flagellate, lamblia intestinalis, attracted attention in England in. the early years of the war when the disease first reached this country from the Eastern fronts. Since 1916, with the exception of Clifford Dobell's report(1), hardly any further reference to the disease has been made in English medical literature. I can find no clinical study of the infection published in this country though many papers on the subject have appeared in America.

This paper is based upon the study of 23 children infected with lambli. and has been largely written without previous reference to the publications of other observers. The conclusions reached are (1) that the infection is now by no means a rarity in hospital practice amongst children; (2) that it produces a chronic enteritis; (3) that the resultant diarrhœa is often severe enough to cause the subjects of the disease to be considerably below their proper weight, and occasionally will produce retarded development anit diminution of growth, suggesting that in lambliasis we have a further possible cause of infantilism of the enteritic type; (4) that even in children true " carriers" may be found, infected with lamblia, but without symptoms.

\section{Frequency.}

Lamblia infections have only become common in England since the war. C. Dobell(1), reporting in 1920 on the occurrence of intestinal protozoa in the inhabitants of Great Britain, gave the carrier-rate of lamblia as $18-27 \%$ of people and states that the protozoon is especially common in the fæces of children. My colleague, H. Perkins ${ }^{(6)}$, in 1921 examined for protozoa the stools of 120 children admitted consecutively to the medical beds at Paddington Green Children's Hospital. Lamblia was found in seven cases, a proportion of $5.8 \%$. The inclusion of a considerable number of infants in this series probahly makes the percentage of infected cases unduly low. In the last four and a half years lamblia has been found in the stools of 23 children who were under treatment at the hospital for intestinal disorders.

In my experience the infection is very much commoner in the childran of the hospital class than in those dealt with in private practice. In $a$. considerable number of fæcal analyses in the latter group I can only recall one case where lamblia was found, that of a child lately returned from Athens.

Sex and Age.

In the 23 cases, 14 were boys and nine girls, a proportion of rather more than three to two. All ages were represented: the youngest child yet found infected was 3 months old(2). 


\section{Symptoms.}

Lambliasis in children may be found in three groups of cases :-

(1) True Carriers. It seems undoubted that even in children true carriers showing no symptoms of the infection may be found. Of the first series of seven cases already mentioned, three showed no intestinal symptoms at all. In this type the number of lamblia cysts found is very small, but whether this is due to the infection's being very mild or merely to the fact that the number of cysts evacuated is greatly increased during diarrhœa, I do not know.

(2) Mixen Conditions. Lamblia may be found in the stools of children suffering from other types of intestinal derangement. In the present series of cases it was found in one case of severe, relapsing and ultimately fatal dysentery, and the same association has becn noted several times in adults. It was also present in two cases of coliac disease, but it is evidently not common here as it has been discovered only twice in more than fifty cœliac cases. In one or two instances in the series lamblia has been associated with an excess of streptococci in the stools, but in the majority of cases the intestinal flora have been normal. I have not found lambliasis to be associated with, nor conducive to, abdominal tuberculosis.

From these resuits there seems no evidence that disorders of the intestine predispose towards infection by lamblia.

(3) Lambla Extreritis. In the great majority of the 23 cases of this series the children were brought to hospital for chronic diarrhœa and no other explanation of this symptom could be found than the presence of lamblia in the stools, usually in very large numbers.

The diarrhœa persists for years, sometimes better, sometimes worse, but rarely completely absent even for a day. At the onset of the illness the number of stools may be as many as eight-twelve a day; later it is usually two-four daily; and after some years it may sink to one-two daily. As in all types of diarrhœa in children the bowels are apt to be moved directly after the taking of food. The diarrhœa is of the type associated with enterocolitis : the motions are loose, show the presence of all kinds of undigested food and a considerable quantity of mucus. Blood does not appear in the stools of uncomplicated lamblia cases. In some instances, owing to intestinal hurry and clefective absorption, an excess of fat appears in the stools giving rise to a suggestion of cœliac disease. In seven cases of the present series the stools appeared fatty and were analysed for me by Dr. Perkins. The

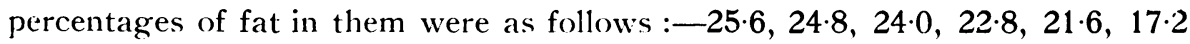
and 10.6. These figures do not reach anything like the proportions of fat found in coeliac disease in its diarrhœic stages, but it is not improbable that in a young child with a rich milk diet, lamblia enteritis could produce stools containing a higher percentage of fat than these I have quoted. In one 
instance of cœliac disease whose stools showed the presence of a few lamblia cysts, the percentage of fat in the dried fæces amounted to $63.2 \%$. This figure was obtained when the diet was similar to that of the lamblia cases quoted above : on a low-fat diet, the percentage dropped to $22.0 \%$.

The abdomen is usually prominent, but not excessively so. It looks the largest part of a thin child. The spleen is not enlarged and nothing abnormal can be felt within the abdomen.

Constitutionally these children, in the chronic stages, do not appear to be much poisoned or ill. They have none of the mentality of the chronic invalid child nor the peculiarities of the cœliac patient. They are lively enough and hungry. Their colour is usually good. They tend to be thin and considerably below the average weight for their age. The growth in height is retarded in some cases. In one curiously delicate child, very small at birth, the growth was said to have actually stopped. So far as I have been able to observe the development of these children, growth and development are not interfered with to anything like the degree which may obtain in coliac disease. In this the dwarfing is a toxic effect and may be very severe : in lambliasis it appears in milder degree and is due to deprivation only.

I quote the two cases of the series in which diarrhœa had lasted for the longest time, namely, ten and eight years respectively :-

Robert H., born September, 1911. In 1915 had a severe attack of liarrhœa which produced drowsiness and thirst. The diarrhœa has continued ever since. The bowels act three or four times a day, especially when food is taken. He has wasted a little and his growth has been slow. Measles in 1915; scarlatina, 1917. October, 1920, was first seen. Height 47 ins. (average for age, 50 ins.). Weight, 52 lbs. 6 ozs. (average, 601 lbs.). Secondary dentition represented by only one upper and two lower central incisors. Abdomen enlarged; nothing abnormal felt. Stools, two-four daily, contain much undigested food; striated muscle fibre; mucus; no excess of fat (10.8\% of dried fæces); very many lamblia cysts. Gained some weight as an in-patient for four weeks. 1923. Acute appendicitis; appendix removed without having any effect on the diarrhœa. July, 1925. Now nearly 14 years old. Still has diarrhœa persistently, but it is much less than formerly, not often more than two motions a day. Abdomen is slightly full in appearance. The boy looks well; is thin, but very active and wiry; boxes and swims. Is growing faster. Height, $58 \frac{1}{8}$ ins. (average, $59 \frac{1}{8}$ ins.). Weight, $82 \frac{1}{1}$ lbs. (average, $92 \mathrm{lbs}$.).

Evidently here the symptoms are now tending to subside and the harm done to become less; normal height has been nearly attained.

Kathleen J., born October, 1912. Diarrhœa and enlarged abdomen since 1917; has attended many doctors for these two symptoms. In October, 1921, was notified as "tuberculous bowels"; bowels then acted five-six times daily, motions pale, offensive, liquid, large, contained mucus, but never blood. In September, 1923, she was referred to me as a possible case of cœliac disease. She was then obviously stunted in growth, her weight was $55 \mathrm{lbs} .2$ ozs. (average for age, $68 \mathrm{lbs}$.). The abdomen was prominent. She had a high colour and her general condition was good. She was passing three-four stools daily. Stool repcrt by Dr. Perkins: "Does not look like a cœliac stool, much undigested food, mucus, great numbers of lamblia cysts ; fat $17.2 \%$ of dried fæces ; flora normal." July, 1925. Still has two-three stools daily. She looks very well, has a high colour. Shows no mammary development. Height $51 \frac{1}{4}$ ins. (average for age, 57 ins.). Weight, $64 \frac{1}{2}$ lbs. (average, 84 lbs.). 
The effect of the infection on the heights and weights of some additional unselected cases is shown in the following table :-

\begin{tabular}{|c|c|c|c|c|}
\hline \multirow{2}{*}{$\begin{array}{l}\text { Case } \\
\text { No. }\end{array}$} & \multirow{2}{*}{ Age. } & \multirow{2}{*}{$\begin{array}{c}\text { Length of } \\
\text { Diarrhœa. } \\
\text { Years. } \\
\end{array}$} & \multicolumn{2}{|c|}{ Comparison with Normal. } \\
\hline & & & $\begin{array}{l}\text { Height. } \\
\text { Inches. }\end{array}$ & $\begin{array}{c}\text { Weight. } \\
\text { lbs. }\end{array}$ \\
\hline 1 & $\begin{array}{l}9 \frac{1}{2} \\
14\end{array}$ & $\begin{array}{r}5 \\
10\end{array}$ & $\begin{array}{l}-3 \\
-1\end{array}$ & $\begin{array}{l}-8 \\
-9 \frac{3}{4}\end{array}$ \\
\hline 2 & $\begin{array}{l}11 \\
12 \frac{3}{4}\end{array}$ & $\begin{array}{l}6 \frac{1}{4} \\
8\end{array}$ & $\begin{array}{c}? \\
-5 \frac{3}{4}\end{array}$ & $\begin{array}{l}-12 \frac{7}{8} \\
-19 \frac{1}{2}\end{array}$ \\
\hline 3 & $\begin{array}{l}3 \frac{3}{4} \\
5 \frac{1}{2}\end{array}$ & $\begin{array}{l}3 \frac{1}{4} \\
5\end{array}$ & $\begin{array}{l}-1 \frac{1}{2} \\
-2 \frac{1}{2}\end{array}$ & $\begin{array}{l}-5 \\
-6 \frac{7}{8}\end{array}$ \\
\hline 4 & 11 & 3 & $-4 \frac{5}{8}$ & -19 \\
\hline 5 & $9 \frac{1}{2}$ & 2 & $-1 \frac{3}{8}$ & $-12 \frac{1}{2}$ \\
\hline $6^{*}$ & 12 & $2 \frac{1}{2}$ & -9 & $-31 \frac{1}{4}$ \\
\hline 7 & 11 & $1 \frac{1}{2}$ & $+\frac{1}{2}$ & -7 \\
\hline 8 & 4 & ? & -4 & -13 \\
\hline
\end{tabular}

* Very small from birth : has stopped growing : same size as sister aged 9.

Complications.

In the series of 23 cases, one developed prolapse and another acute appendicitis. Both these conditions are such as might be expected to arise in persistent enterocolitis in children.

Diagnosis.

In cases of long-lasting diarrhœa in children where examination shows no other abnormality than a heavy infection by lamblia, it is not unreasonable to assume that this is the cause of the symptoms. Such cases as have been detailed above are of a peculiar type; for diarrhœa to last for eight or ten years in early life has been hitherto a very unusual thing and such cases are well explained by the fact that lamblia infections are much less uncommon now than formerly. These cases bear but the most superficial resemblance to those of abdominal tuberculosis and can easily be distinguished from bacterial infections of the dysenteric types; nor are they like instances of nervous diarrhœa. 
It is worth pointing out that as far as the history of illness goes, the lamblia infection resembles cœliac disease more than any other disorder. In both conditions there is a history of persistent diarrhœa, some enlargement of the abdomen and retardation of growth, although the symptoms are usually far more severe and the invalidism far greater in coeliac disease than in lambliasis. Further, the similarity between the two conditions may be increased by the fact that from time to time stools apparently containing an excess of fat may occur in the lamblia cases. I have several times sent fæcal specimens to be analysed on the suspicion of the presence of cœliac disease and received back a report of lamblia infection. If the stool is examined there is little difficulty in distinguishing between the two conditions. Besides the presence of the protozoon the lamblia stool is that of a chronic enterocolitis. It contains much undigested food and mucus and perhaps is slightly fatty. In cœliac disease the great abnormality is the excess of fat without evidence, or without persistent evidence, of enteritis or any corresponding degree of maldigestion of the non-fatty foodstuffs( ${ }^{(5)}$.

A comparative study of lamblia cases with coliac cases will convince the observer that coliac disease is not due to an entero-colitis, in spite of the superficial resemblance of the symptoms in the two groups of cases.

\section{Course and Prognosis.}

As I have already stated the infection by lamblia does not produce any serions degree of illness, though it causes wasting and retarded growth. The diarrhoea seems to be at its worst at the onset of the infection and to persist for many years with some degree of severity. As time passes the diarrhœa tends to diminish until at last it ceases to be even an inconvenience. The infection, however, appears to persist throughout childhood.

It is probable that the most harmful effects of the infection occur in the youngest subjects. I certainly do not agree with those authors who state that the infection is harmless; as far as children are concerned this is untrue.

\section{Treatment.}

Claims have been made for various lrugs that they are capable of ridding the intestine of lamblia. In no case have such claims been substantiated. Lately an arsinic preparation, Stovarsol, has been credited with this power by Marchoux(3) (4), but this is frankly denied by Gillmore(2). The drug is given by the mouth and is easily administered to children. I have had no success in my trial of it. Ordinary disinfectants appear useless.

It has to be remembered in connection with all claims to cure lambliasis that the flagellate will spontaneously disappear for a time from the stools. Tests to be of conclusive value should be made on several consecutive days after the daily administration of saline purges. Up to the present no drug appears to have passed such a test as this. 
Where the diarrhœa is doing sufficient harm, improvement can be quickly brought about by such measures as rest, colon lavage, careful dieting and the administration of bismuth, with or without opium.

My thanks are due to my colleague, Dr. T. Pearse Williams, for access to some of his cases ; to Dr. R. King, Medical Officer of Health for Ilkeston, for the after-history of the second case quoted here; and to Dr. H. Perkins for his numerous pathological reports.

\section{REFERENCES}

1. Dobell, C. : Brit. Med. Journ., 1921, i., 276.

2. Gillmore, J. G. : Extra Pharmacopœia, Lond., 18th Ed., 1924, i., 530.

3. Marchoux, E. : Bull. Soc. Path. Exot., Paris, 1923, xvi., 325.

4. Marchoux, E. : Paris Méd., 1924, ii., 421.

5. Miller, R.: Lancet, 1926, i., 330.

6. Perkins, H. : Brit. Med. Journ., 1921, i., 364. 